\title{
INTEGRISMO CATÓLICO NA ESPANHA DO SÉCULO XIX
}

\section{Catholic integrism in Spain in the nineteenth century}

\author{
Marcos Gonçalves*
}

MOLINER PRADA, Antonio. Fèlix Sardà i Salvany y el integrismo en la Restauración. Barcelona: Universitat Autònoma de Barcelona, Servei de Publicacions, 2000. 294 p.

Antonio Moliner Prada é professor titular de História Contemporânea na Universidade Autônoma de Barcelona e especialista em História da Espanha do século XIX. O autor congrega em suas reflexões da época estudos sobre os partidos políticos espanhóis, pesquisas sobre o impacto das revoluções burguesas e dos movimentos sociais e, especialmente, análises sobre a relação entre o catolicismo, o anticlericalismo e a evolução do pensamento liberal. Essa trajetória intelectual, portanto, o credencia como interlocutor privilegiado a respeito da obra e do pensamento político e religioso do sacerdote catalão Fèlix Sardà i Salvany (1841-1916). Mencionese que Moliner Prada, em trabalho precedente, já estabelecera padrões de análise por meio de breve incursão historiográfica sobre a mentalidade antimaçônica da personagem. ${ }^{1}$

Em abordagem mais ampla, e disposta a superar o marco puramente hierárquico nos estudos sobre o catolicismo institucional, Moliner Prada também almeja transcender os próprios referenciais biográficos de Sardà i Salvany. Essa operação metodológica entrelaça os núcleos da religião católica e da cultura espanholas do século XIX ao seu núcleo político, cuja marca decisiva durante o período distinguiu-se por conflitos e disputas entre movimentos liberais e laicizantes, movimentos regionalistas e correntes católicas conservadoras. É nesse sentido que o autor investiga a vertente do chamado integrismo católico através da extensa produção do religioso objeto de sua pesquisa. A experiência de vida de Sardà i Salvany é, assim,

* Doutorando do Programa de Pós-Graduação em História da Universidade Federal do Paraná

1 MOLINER PRADA, Antonio. Antimasonería e integrismo religioso antimasónico de Fèlix Sardà i Salvany. In: BENIMELI, J. A. Ferrer. (Coord.). La Masonería española y la crisis colonial del 98. v. 1. Zaragoza, Symposium Internacional de Historia de la Masonería Española, 1999. p. 179-201. 
interpretada em chave não linear, pela qual se descarta a possibilidade de escolhas livres de contradições ou determinadas por um desígnio reto ou inato. Nessa experiência, se desenrolam os dilemas próprios ao tempo em que a personagem viveu, bem como se destacam a capacidade e os limites de intervenção da mesma personagem sobre a fugidia realidade histórica.

Na perspectiva de Moliner Prada, são questões centrais: 1) definir significados e influências da tendência integrista no âmbito do catolicismo espanhol; 2) estabelecer as possíveis modelagens históricas pelas quais se articula a inserção do pensamento e do ativismo que realçam o papel de Sardà i Salvany na mentalidade específica do integrismo.

Nascido em 23 de maio de 1841, na cidade de Sabadell, e oriundo de rica família industrial da Catalunha atuante no ramo da tecelagem, Sardà foi herdeiro do absolutismo político e do tradicionalismo donosianos. ${ }^{2}$ Gozou de grande popularidade na Catalunha, em toda a Espanha, na América hispânica e nos círculos católicos europeus de fins do século XIX. Sua licenciatura em teologia pelo Seminário de Valência em 1864, também demonstra que recebeu influências de modelos literários e eclesiásticos do jesuitismo. Ordenado sacerdote em 1865, atuou como catedrático de latim no Seminário de Barcelona até 1868, ano em que a instituição foi fechada por força dos decretos do novo governo liberal.

As idéias de Sardà, expostas em sentido coloquial e reiterativo durante várias décadas, remontavam às formas populares de apologética e eram orientadas pelo desencanto com o mundo moderno. Pretendia obstinadamente sensibilizar aos católicos espanhóis quanto à nocividade das políticas secularizantes introduzidas na Europa pela revolução francesa e por diversos segmentos do liberalismo. Depois da revolução liberal de 1868 e do sexênio democrático correspondente, Sardà empenhou-se na restauração, ou fundação, de um Estado teocrático espanhol, mediante o impulso da catequese e da expansão de escolas católicas. O associativismo leigo em todos os níveis, sob controle da Igreja Católica, e a revitalização da imprensa e da propaganda religiosa eram os mecanismos mais idôneos, na ótica de Sardà, para frear as atividades dos clubes e ateneus liberais, dos

2 Donoso Cortés é um dos representantes do ultraconservadorismo católico do século XIX. Notas características de seu pensamento seriam o catastrofismo apocalíptico pelo temor de uma revolução universal e o avanço das idéias socialistas; uma irreconciliação entre a verdade e o erro nas antinomias revelação/filosofia, igreja/revolução; e uma analogia existente entre Deus e sociedade, entre religião e política, entre igreja e civilização, de forma que se impõem à sociedade civil, como única possibilidade, os princípios da política cristã. 
círculos republicanos, das casas do povo socialistas, das lojas maçônicas e das atividades do sindicalismo revolucionário.

Esse horizonte mínimo, sob a intensa militância de Sardà, permite a Moliner Prada abrir a reflexão para uma série de encaminhamentos. Nos dois primeiros capítulos ("La obra del doctor Sardà i Salvany", p. 17-62; "La controversia en torno a la publicación de El liberalismo es pecado", p. 63-77), o autor destaca com rara precisão analítica o desempenho intelectual de Sardà i Salvany, avaliando seu estilo como polemista e propagandista católico. Escritor enérgico e infatigável, e que recolhia casos do cotidiano ordinário para imprimirlhes valor moral, Sardà contribuiu na mediação de interesses entre a hierarquia religiosa e as camadas populares católicas organizadas para o desenvolvimento da propaganda. Não obstante uma possível posição de independência das organizações católicas, Sardà definia a propaganda católica como

el trabajo individual o colectivo de todo fiel católico para la propagación, defensa, aumento y esplendor de su fe, aparte de los que constituye la función jerárquica y oficial de la Iglesia docente, pero siempre bajo la dirección y autoridad en todo y para todo de esta misma Iglesia. (p. 32)

Parte constitutiva essencial do projeto integrista católico de Sardà foi a publicação, em 1884, de El liberalismo es pecado. Trata-se de sua obra mais difundida na Espanha. El liberalismo... conheceu oito edições em poucos meses e, em 1906, havia chegado à sexagésima edição. Considerado a bíblia do integrismo espanhol, esse opúsculo de pouco mais de duzentas páginas traça um fecundo painel que condena o liberalismo como doutrina e sistema político. E se converte, segundo Moliner Prada, em uma apologia da intolerância religiosa, um guia prático de recomendações e regras que haveriam de observar os bons católicos para aceitarem a supremacia do poder espiritual sobre o temporal, e para que se mobilizassem na instalação de uma jurisdição plenária da Igreja Católica sobre a sociedade (p. 75). É em torno desse quadro de referência que Moliner Prada acomoda a estrutura conceitual do integrismo católico.

Numa definição meramente descritiva, o integrismo é uma mentalidade de grupos católicos investidos de códigos de comportamento religioso ou político em conflito com as formas de vida marcadas a fundo em variados 
tempos por também variados processos de secularização. Partindo do campo religioso doutrinal, mas superando esse registro para atingir uma dimensão ética constitutiva do coletivo, o integrismo representa uma atitude no sentido de impregnar de catolicismo todas as esferas da vida social.

Para Moliner Prada, o integrismo espanhol, na sua modalidade política, ancora-se, entre outras bases inspiradoras, na corrente de católicos intransigentes que, sob a liderança de Candido e Ramón Nocedal, formaram o partido integrista em 1888, logo em seguida à ruptura com o monarquismo carlista moderado, desejoso em estabelecer um canal de diálogo com os liberais. Contudo, a repulsa radical ao liberalismo e a adesão sem condicionantes às teses do Syllabus de Pio IX (1864), propiciaram ao integrismo espanhol construir uma simbiose entre as premissas religiosas e os princípios ideológico-políticos, catalisando sensivelmente boa parte da audiência católica espanhola. O objetivo dessa aliança era instaurar um regime de cristandade. Ou, em outras palavras, a plataforma dos integristas era integrar religião e política pela restauração de uma Espanha imperial, primeiro católica, depois monárquica. Submissa ao papa e à igreja romana, a españolidad integrista seria amparada pela convicção de que a providência divina atuaria em favor das suas pretensões, sem, claro está, abdicar de uma sistemática propaganda por meio dos mais variados dispositivos de comunicação social disponíveis à época.

À corrente integrista liderada por Sardà i Salvany, coube o papel não só de conciliar, mas eliminar, o hiato entre a ordem social mundana e a ordem espiritual. Porém, a política em si mesma era vista com desprezo e não respondia aos desígnios de uma sobrenatureza religiosa se não fosse um instrumento de apoio incondicional ao catolicismo:

La política, el meterse en politica o hacer política, está mal visto y es objeto de desprecio por parte de los agentes decentes. Sólo tiene sentido y es bien visto si se trabaja en el terreno de la política con el único objeto de defender la religión; entonces no es meterse en política, es ocuparse solamente en Religión. En qualquier caso, el católico y todavía más aún el clero no puede apoyar con su voto a los partidos liberales, porque professan ideas errôneas y contrarias a los principios de la religión. (p. 115, grifos no original)

A ênfase crítica ao liberalismo, todavia, não encobre outras frentes de luta abertas por Sardà. No periodismo, Sardà impulsionou a publicação da Biblioteca Popular de Barcelona, que, a partir de 1871, tomou o nome de 
Revista Popular, "convirtiendóse en un semanario ilustrado, de instrucción, de piedad y de recreio, siempre de actualidad y de interes palpitante", e, na qual, assumiu a direção por mais de quarenta anos (p. 29). Através de um mergulho nos escritos do sacerdote catalão, Moliner Prada evidencia a multiplicidade de questões que envolviam sua atividade. $\mathrm{O}$ antiprotestantismo, a incompatibilidade entre catolicismo e socialismo, os movimentos operários e a laicização progressiva do sistema educacional foram traduzidos por Sardà pela ótica de um pessimismo antropológico característico da cosmovisão integrista.

$\mathrm{O}$ integrismo de Sardà postulava em nome da fé e da tradição uma postura excludente dos católicos que buscavam a consolidação de um regime liberal, a introdução de certa tolerância religiosa e a secularização do Estado e da sociedade (p. 265). Além de constituir um grupo de pressão dentro da Igreja espanhola para conseguir o controle eclesiástico, o setor integrista encabeçado por Sardà radicalizou suas posições ideológicas. Contrários a todo tipo de transações, afirmavam a integridade

de los derechos soberanos de Dios sobre los hombres y sobre las sociedades organizadas en Estados, y al mismo tiempo identifican los derechos de Dios con los derechos de la Iglesia. (p. 263)

Adepto da polêmica tese de que o integrismo se realiza como uma variante católica do fundamentalismo ${ }^{3}$, o estudo de Moliner Prada também denota originalidade ao propor uma compreensão que toma distância de outras interpretações quanto à gênese da modalidade integrista no campo católico. Autores como Klaus Kienzler ${ }^{4}$, e mesmo apologistas da corrente integrista como Jean Madiran ${ }^{5}$, concordam que o termo integrismo é uma figura histórica concreta a partir da condenação do modernismo religioso pela encíclica Pascendi Dominici Gregis (1907), de Pio X. Nesse último sentido, a terminologia seria apropriada para designar uma oposição intransigente às tentativas de profundas reformas doutrinárias, metodológicas e

3 "El término fundamentalismo, muy de moda en nuestros dias, se aplica en el sentido de todo creyente de cualquier religión que interpreta el mundo y aspira a organizar la sociedad de acuerdo con las pautas de su fe religiosa. El catolicismo integrista del siglo XIX es, en este sentido, fundamentalista al condenar el pensamiento moderno, el liberalismo, la democracia y el socialismo." (p. 9)

4 KIENZLER, Klaus. El fundamentalismo religioso: cristianismo, judaísmo, islamismo. Madrid: Alianza, 2000

5 MADIRAN, Jean. L'intégrisme: histoire d'une histoire. Paris: Nouvelles Editions Latines, 1964. 
exegéticas defendidas por alguns teólogos católicos que, da mesma forma, exigiam uma maior colegialidade de decisões no âmbito da Sé romana. Os representantes da ultra-ortodoxia baseada na órbita do papado se autodenominaram "católicos integrais", justamente para assinalar tal oposição e afirmar o caráter indissolúvel do catolicismo. Diga-se, uma oposição estabelecida e majoritária que reivindicava uma sociedade confessional, de fé católica integral, apoiada nos dogmas e no suposto de inerrância literal do texto papal.

Ao contrário, quando Moliner Prada investe sobre o universo intelectual e recupera as práticas de Sardà i Salvany, contribui não somente para estabelecer a precedência histórica do integrismo como possível categoria de análise em relação a outras investigações, mas, sobretudo, expõe especificidades culturais próprias a projetos eclesiásticos determinados, e estimula a produção de pesquisas por comparação. É pertinente reconhecer que a sua abordagem precipita ainda mais o campo de incertezas em que se equilibra o conceito de integrismo. No entanto, sem essas incertezas, podemos dizer que nossa capacidade de apreensão sobre tal objeto estaria reduzida ou mesmo negligenciada. 